\title{
'JANUÁRIA': NOVA AMEIXA DE MATURAÇÃO TARDIA ( $\left.{ }^{(}\right)$
}

\author{
FERNANDO ANTONIO CAMPO DALL'ORTO $\left({ }^{2,5}\right)$, MÄRIO OJIMA $\left({ }^{2}\right)$, \\ WILSON BARBOSA $\left({ }^{2,6}\right)$, ANTONIO FERNANDO CAETANO TOMBOLATO $\left({ }^{2}\right)$, \\ ORLANDO RIGITANO $\left({ }^{3}\right)$, FERNANDO PICARELLI MARTINS $\left({ }^{4,5}\right)$ \\ e HÉLIO JOSÉ SCARANARI $\left(^{4}\right)$
}

\begin{abstract}
RESUMO
'Januária' (IAC K-52) é um novo cultivar de ameixa obtido no Instituto Agronômico, dentro do seu programa de melhoramento varietal. Provém da polinização aberta do 'Kelsey Paulista', e tem como características principais a alta produtividade das plantas e a maturação tardia dos frutos, que são graúdos, globosocordiformes, de coloração vermelha e de sabor doce-acidulado suave.,
\end{abstract}

Termos de indexação: ameixa, 'Januária', novo cultivar, maturaçāo tarđia.

\section{INTRODUÇÃO}

Os trabalhos de melhoramento varietal da ameixeira (Prunus salicina Lindl.), desenvolvidos na Seção de Fruticultura de Clima Temperado, a partir de 1966, resultaram no lançamento comercial dos seguintes cultivares pouco exigentes de frio: Carmesim (IAC 2-41), Rosa Paulista (IAC 2-51), Grancuore

( ${ }^{1}$ ) Trabalho desenvolvido com Auxílio à Pesquisa da FAPESP. Recebido para publicação em 1 o de junho de 1984.

( ${ }^{2}$ Seção de Fruticultura de Clima Temperado, Instituto Agronômico (IAC), Caixa Postal 28, 13100 - Campinas (SP).

$\left.{ }_{4}^{3}\right)$ Divisāo de Horticultura, IAC.

(4) Estação Experimental de Jundiaí, IAC.

(5) Com bolsa de suplementação do CNPq.

( ${ }^{6}$ ) Com bolsa de aperfeiçoamento do $\mathrm{CNPq}$. 
(IAC 2-16), Gema-de-Ouro (IAC K-43), Golden Talismã (IAC K-16) e Rosa Mineira (IAC K-48) (OJIMA et alii, 1978; 1979; 1983; RIGITANO \& OJIMA, 1973). A evolução da cultura da ameixeira no Estado de São Paulo tem sido expressiva nos últimos doze anos, passando de 75.000 plantas cultivadas, em 1972, a cerca de 500.000 nos dias atuais. Esse fato se deve d̀ aceitação, tanto da parte dos produtores, quanto do público consumidor, dos novos cultivares IAC, especialmente o Carmesim, que vem substituindo os antigos cultivares Kelsey Paulista e Roxa de Itaquera.

De uma série de outras seleçóes promissoras, que vêm sendo observadas nos lotes experimentais do Instituto Agronômico, foi possível eleger uma nova ameixa, designada por IAC K-52, de boas características agronômicas, e cuja apresentação constitui o objeto do presente trabalho.

\section{MATERIAL E MÉTODOS}

No ano agrícola de 1969/70, colheram-se na Estaçæo Experimental de Jundiaí 1.600 sementes provenientes de polinização livre do cultivar Kelsey Paulista. Tais sementes foram submetidas, na Seção de Fruticultura de Clima Temperado, em Campinas, à estratificação normal, a frio úmido, por dois meses, e semeadas em canteiros de terra, sob ripado, dando origem a 81 "seedlings" aproveitáveis. Estes, envasados em recipientes de plástico, foram plantados na Estação Experimental de Jundiai, no lote de seieção, em 1971, sob espaçamento de 3,0 x 1,0m.

Nos exames efetuados nesse lote, a partir de 1973, sobressaiu-se a planta registrada como K-52, ou seja, o $52^{\circ}$ "seedling" do 'Kelsey Paulista', por sua sanidade e grande produtividade de frutos de belo aspecto e maturação tardia.

Para melhor avaliação desse material, procedeu-se, em 1980, à sua multiplicação, enxertando-o sobre pés francos do pessegueiro 'Okinawa', e as mudas foram plantadas, no ano seguinte, no campo experimental da mesma Estação do Instituto Agronômico.

Nas frutificações dos ciclos agrícolas de 1982/83 e 1983/84, procedeu-se ao exame das características das plantas, ao controle da produção e à minuciosa análise pomológica.

\section{RESULTADOS E DISCUSSÃO}

A avaliação das plantas enxertadas, sob aspectos vegetativos e produtivos, e a análise dos frutos, permitiram confirmar as superiores qualidades 
dessa nova ameixa. Com o nome de 'Januária' - que faz lembrar sua maturação tardia - começou a ser fornecida aos fruticultores interessados no seu cultivo, a partir de 1984, sob a forma de borbulhas para enxertia.

Descrição do novo cultivar: Fruto de tamanho médio a grande, 60 a 80 gramas, globoso-cordiforme; sutura nítida, dividindo o fruto em duas partes ligeiramente desiguais; cavidade peduncular estreita e rasa; pedúnculo medianamente longo. Película espessa, de coloração vermelho-escura com fundo esverdeado, nos frutos "de vez", e vermelha viva com fundo amarelo-róseo, nos maduros, e revestida de uma leve camada de pruína esbranquiçada. Polpa rósea, com manchas claras nos frutos "de vez", tornando-se bem avermelhada nos maduros; textura firme, macia e gelatinosa; sabor agradável, doce-acidulado, franco, pouco aromático, com baixa acidez junto a película e ao caroço; teor de açúcares ao redor de $12^{\circ}$ Brix, e acidez $\mathrm{pH} 4,4$; caroço de tamanho médio a pequeno, praticamente solto no interior de ampla cavidade que se alarga na porção distal, à semelhança do que ocorre nos frutos do 'Kelsey Paulista'.

Planta medianamente vigorosa, com enfolhamento moderado; folhas de tamanho médio, acuminadas e de coloração verde-escura. $O$ florescimento e a frutificação processam-se em abundancia todos os anos, tanto nos ramos novos e longos, quanto nos esporðes, o que indica sua baixa exigência de frio para hibernação. A produtividade de plantas jovens tem sido das mais elevadas, constatando-se colheitas médias de $12 \mathrm{~kg}$ e $36 \mathrm{~kg}$ por ameixeira de 1,5 a 2,5 anos de idade respectivamente. A época de maturação é tardia: nas condiçбes de Jundiai, a safra tem ocorrido em fins do mês de janeiro, fato que, por conotação gráfica, levou a dar ao material o nome 'Januária'.

Nas plantas em estudo, submetidas aos tratamentos fitossanitários rotineiros, não se constataram doenças criptogâmicas dignas de registro; nem mesmo os frutos, que apresentavam algumas "punturas" de mosca-das-frutas, mostraram incidência significativa de podridão-parda.

Perspectivas do novo cultivar: A alta produtividade e a rusticidade das plantas, bem como a produção de frutos graúdos de maturação tardia, constituem os maiores méritos da ameixa 'Januária' (IAC K-52). Sua época de maturação ocorre em seqüência à do 'Kelsey Paulista', possibilitando, assim, ampliar o período da safra de ameixas em São Paulo. Deverá, pois, servir como importante cultivar opcional, mormente para a formação de novos pomares nas regiðes mais frias do Estado, onde as condiçðes climáticas possibilitariam a produção ainda mais tardia de ameixas de elevada cotação no mercado. Finalmente, testes preliminares de utilização culinária de ameixa 'Januária' indicaram tratar-se de excelente matéria-prima para a elaboração de compotas e licores. 


\section{SUMMARY}

'JANUÃRIA' - A NEW LATE RIPENING PLUM

'Januária' (IAC K-52) is a new plum cultivar selected as a result of a breeding program conducted at the Instituto Agronômico, Campinas, State of São Paulo, Brazil. It was obtained as a seedling from the cultivar Kelsey Paulista open pollinated. Its most important characteristics are low-chiling requirement, high productivity, and late ripening of large handsome fruits.

Index terms: plum, 'Januária', new cultivar, late ripenning.

\section{REFERÊNCIAS BIBLIOGRÁFICAS}

OJIMA, M.; RIGITANO, O. \& CAMPO DALL ORTO, F.A. Melhoramento da ameixeira - novos cultivares para o clima paulista. Campinas, Instituto Agronômico, 1978. 11p. (Boletim técnico, 56)

vos cultivares de ameixa (Prunus salicina Lindl.) pouco exigente de frio. In; CONGRESSO BRASILEIRO DE FRUTICULTURA. 5., Pelotas, RS, 1979. Anais. Pelotas, Sociedade Brasileira de Fruticultura, 1979. v.2, p. 708-715. Mineira' - novo cultivar IAC de ameixa pouco exigente de frio. Bragantia, Campinas, 42:233-238, 1983. (Nota, 1)

RIGITANO, O. \& OJIMA, M. 'Carmesim' nova ameixa para o Estado de São Paulo. Campinas, Instituto Agronômico, 1973. 20p. (Boletim, 205) 